\title{
Impact of organophilic clay on rheological properties of gasoil-based drilling muds
}

\author{
Cheikh Bergane $^{1} \cdot$ Larbi Hammadi $^{1}$
}

Received: 17 June 2020 / Accepted: 19 September 2020 / Published online: 27 September 2020

(c) The Author(s) 2020

\begin{abstract}
In this study, the impact of VG69 organophilic clay on the rheological properties of gasoil-based drilling muds (invert emulsions) was investigated. The flow curves of gasoil-based drilling muds as a function of the dose of VG69 organophilic clay were analyzed by the Casson model. The addition of VG69 organophilic clay with a quantity range between 0 and $5 \mathrm{~g}$ in gasoil-based drilling muds induces an increase in the yield stress and the viscosity at an infinite shear rate of drilling muds. It is also proven that the addition of VG69 organophilic clay leads to an increase in the viscoelastic and thixotropic properties of the drilling muds. The study of the stability of gasoil-based drilling muds by centrifugation showed that for a quantity of VG69 organophilic clay lower than $3 \mathrm{~g}$, the stability of the drilling muds increases and for a quantity of VG69 organophilic clay higher than $3 \mathrm{~g}$, their stability decreases. The results obtained showed that the addition of $3 \mathrm{~g}$ of VG69 organophilic clay to the gasoil-based drilling mud increased the yield stress by $230 \%$, the viscosity at an infinite shear rate by $3.4 \%$ and it improved the mud stability by $70 \%$.
\end{abstract}

Keywords Gasoil-based drilling muds · VG69 organophilic clay $\cdot$ Mud stability $\cdot$ rheological properties $\cdot$ Casson model

\section{Introduction}

Drilling muds are used in particular for petroleum drilling and natural gas drilling, but also for simpler drilling, for example intended to produce drinking water. Drilling muds perform several functions, such as cleaning the well, keeping the cuttings in suspension, cooling and lubricating the tool and obtaining information on the nature of the formation drilled by raising the cuttings from the bottom to the surface (Agin et al. 2019; Ibrahim et al. 2017; Medhi et al. 2020; Salehnezhad et al. 2019; Stuckman et al. 2019). Drilling muds are classified into two main categories: water-based muds and oil-based muds (Coussot et al. 2004; Gbadamosi et al. 2019). Today the drilling of high pressure and high temperature is generally used in petroleum and natural gas

Cheikh Bergane

cheikh.bergane@univ-usto.dz;

Berganecheikh.1993@gmail.com

1 Laboratoire de Rhéologie, Transport Et Traitement Des Fluides Complexes (LRTTFC), Faculté D'Architecture Et de Génie Civil, Département d'Hydraulique, Université Des Sciences Et de La Technologie D'Oran (USTO-MB), B.P. 1505, 31000 Oran-EL-M'naouer, Algérie industry (Ali et al. 2020). In order to minimize the cost of drilling and extend the useful life of drilling tools, drilling fluids and their additives are used (Aftab et al. 2017). In petroleum industry, the oil-based drilling muds are often preferred to water-based drilling muds in order to avoid interactions between drilling muds and rocks, especially for drilling under extreme temperature and pressure conditions or in rocks with low permeability and low porosity (Akkal et al. 2013). According to Li et al. (2016) oil-based drilling muds offer hole stability, a very fine filter cake, excellent lubricity and less risk of pipe blockage. The continuous oily phase is usually gasoil which is beneficial from the point of view of the protection of the producing layers, and it is also characterized by plasticity, thixotropy and clogging power. The major problem in oil-based drilling muds is their chemical and rheological instability, which is why many additives have been added to this type of muds to improve their stability. The rheology modifier for gasoil-based drilling muds is normally controlled by organophilic clay (Ali et al. 2020). The addition of organophilic clay offers to oil-based drilling muds a high thermal stability, an ability to swell in an organic medium (gasoil) and a desired rheological properties such as viscosity, high shear thinning behavior, yield stress and thixotropy (Akkal et al. 2013; Msadok et al. 2020).

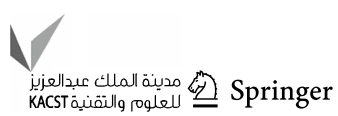


Recently Msadok et al. (2020) used the Tunisian clay modified in order to improve the rheological properties of diesel oil drilling muds. It has been shown that the increase in the percentage of clay modified in diesel drilling muds has led to an improvement in their yield stresses. Mohamed et al. (2018) used an organoclay as a stabilizer for water-in-oil emulsions under high temperature and salinity conditions. It has been proven that the stability of the emulsion increases with increasing organoclay concentration. A new formulation of oil-based drilling muds at high density has been developed by Jiang et al. (2016). It has been demonstrated that the increase in organoclay resulted in an improvement in the stability of invert emulsion oil-water and an increase in the yield stress and viscosity of invert emulsion. A new method was presented by Huang et al. (2016) to improve the rheological properties of oil-based drilling muds by using a hydrogen bonding that replace organoclay to enhance the interactions of water droplets through hydrogen bonding. The results showed that the increase in hydrogen bonding concentration in oil-based drilling muds resulted in increased viscosity and thixotropic behavior. Likewise, the authors demonstrated that when hydrogen bonding is added to the oil-based drilling muds, their stability will be improved. Hermoso et al. (2015) proved that for low organoclay concentration added in oil-drilling mud, the yield stress varies linearly with organoclay concentration and for a higher concentration of organoclay, the yield stress varies according to a power law. Geng et al. (2019) studied the influence of three different organoclay such as the organosepiolite, organo-hectorite and organo-montmorillonite on rheological properties and microstructure of oil-drilling muds. It has been demonstrated that the organo-hectorite is more effective to improve the rheological properties of invert emulsion at high temperature than organo-sepiolite and organo-montmorillonite. In order to improve the rheological properties of water-based drilling muds, Ismail et al. (2016) added the carbon nanotube, nanoparticles and nanosilica in water-based drilling muds. It has been shown that the addition of the nanosilica in water-based drilling muds leads to an amelioration of their plastic viscosity and their yield stress. Likewise, the authors demonstrated that the incorporation of the small concentration of carbon nanotube and nanosilica in water-based drilling muds improve their rheological properties (plastic viscosity and yield point). Zhou et al. (2016) modified montmorillonites by cationic and anionic surfactants in oil-based drilling fluids and studied thixotropic behavior at room temperature and at higher temperatures $\left(200-220^{\circ} \mathrm{C}\right)$. They proved that cationic and anionic organomontmorillonites have a better thixotropy than cationic organomontmorillonites in different oil-water ratio oil-based drilling fluids. Aftab et al. (2020) studied the effect of tween 80/ZnO-Nanoparticles on performances of water-based drilling fluids. It has been clearly demonstrated
Table 1 Physical properties of gasoil

\begin{tabular}{ll}
\hline Density at $15^{\circ} \mathrm{C}$ & $0.828 \mathrm{~g} / \mathrm{cm}^{3}$ \\
Dynamic viscosity at $20^{\circ} \mathrm{C}$ & $5.6 \mathrm{mPa} \mathrm{s}$ \\
Surface tension at $20^{\circ} \mathrm{C}$ & $30.5 \mathrm{mN} / \mathrm{m}$ \\
Flash point & $88^{\circ} \mathrm{C}$ \\
Pour point & $-14{ }^{\circ} \mathrm{C}$ \\
Initial boiling point & $152^{\circ} \mathrm{C}$ \\
Final boiling point & $320^{\circ} \mathrm{C}$ \\
\hline
\end{tabular}

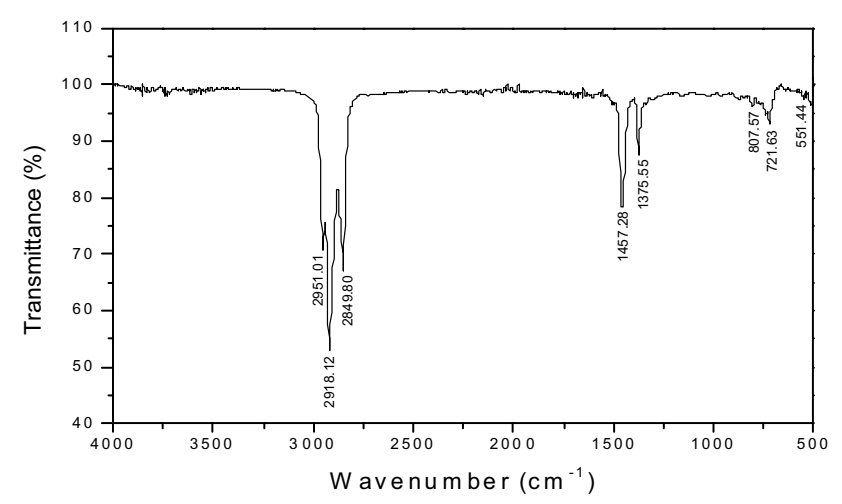

Fig. 1 FTIR spectrum of gasoil

that the addition of $0.7 \mathrm{~g}$ of tween $80 / \mathrm{ZnO}$-Nanoparticles in water-based drilling fluids improve their plastic viscosity by $12 \%$ and their yield point by $71 \%$. They also showed that the addition of $0.7 \mathrm{~g}$ of $\mathrm{T} 80 \mathrm{ZnO}$ in water-based drilling fluids minimized their filtrate to 17 and $30 \%$.

Although many researchers have investigated the rheological behavior of oil-based drilling mud, the results of this article are quite different since we are proposing a new formulation of gasoil-based drilling mud. The main objective of this work is to formulate a gasoil-based drilling mud stable and more efficient with less composition (economical) based on the rheological study.

\section{Materials and experimental methods}

\section{Gasoil and surfactants}

The gasoil used in this study was obtained by the company Naftal. Table 1 shows the physical properties of this gasoil.

The infrared spectroscopic measurement of gasoil was obtained using a PerkinElmer Spectrum Two FT-IR spectrophotometer at room temperature. The spectrum was collected over the spectral range of $4000-400 \mathrm{~cm}^{-1}$. The IR spectrum of gasoil is shown in Fig. 1. The wavenumbers at $2951.01,2918.12$ and $2849.80 \mathrm{~cm}^{-1}$ are attributed to the stretching vibrations of $\mathrm{C}=\mathrm{O}$ and $\mathrm{CH}$. The wavenumbers at 
Table 2 Physical properties of Versacoat

\begin{tabular}{ll}
\hline Density at $20{ }^{\circ} \mathrm{C}$ & $0.91 \mathrm{~g} / \mathrm{cm}^{3}$ \\
Flash point & $27.8^{\circ} \mathrm{C}$ \\
Pour point & $-29.1{ }^{\circ} \mathrm{C}$ \\
Critical micelle concentration $(\mathrm{CMC})$ & $7.79 .10^{-5} \mathrm{M}$ \\
Surface tension at $20^{\circ} \mathrm{C}$ & $35.9 \mathrm{mN} / \mathrm{m}$ \\
\hline
\end{tabular}

Table 3 Physical properties of Versawet

\begin{tabular}{ll}
\hline Density at $20{ }^{\circ} \mathrm{C}$ & $0.95 \mathrm{~g} / \mathrm{cm}^{3}$ \\
Flash point & $91.7{ }^{\circ} \mathrm{C}$ \\
Pour point & $5.9{ }^{\circ} \mathrm{C}$ \\
Critical micelle concentration $(\mathrm{CMC})$ & $2.97 .10^{-3} \mathrm{M}$ \\
Surface tension at $20^{\circ} \mathrm{C}$ & $42.9 \mathrm{mN} / \mathrm{m}$ \\
\hline
\end{tabular}

1457.28 and $1375.55 \mathrm{~cm}^{-1}$ correspond to the symmetrical angular deformation in the plane of $\mathrm{CH}_{2}$ and the asymmetrical angular deformation in the plane of $\mathrm{CH}_{3}$. The wavenumbers at $807.57,721.63$ and $551.44 \mathrm{~cm}^{-1}$ are attributed to the stretching vibrations of the carbonyl compounds corresponding to the side chain esters (Ruschel et al. 2015; Bharath et al. 2020).

Versacoat is a non-ionic surfactant that serves as an emulsifier and Versawet is a cationic surfactant that serves as a wetting agent. These two surfactants have an important role in the formulation of gasoil-based drilling muds whose first function is to lower the interfacial tension between water and gasoil and the second function is to stabilize the gasoil-based drilling muds. The physical properties of surfactants used are shown in Tables 2 and 3.

\section{Organophilic clay}

The organophilic clay used in this study is VG69 organophilic clay (amine-treated bentonite), it is a viscosifier and gelling agent used in oil-based drilling muds to increase carrying capacity and suspension properties, providing support for weight materials and improved cuttings removal, VG69 also aids in filter-cake formation and filtration control. The main components of this organophilic clay are: $\mathrm{S}_{\mathrm{i}} \mathrm{O}_{2}$ (57.787\%), $\mathrm{Al}_{2} \mathrm{O}_{3}$ (7.153\%), $\mathrm{Fe}_{2} \mathrm{O}_{3}(8.768 \%), \mathrm{CaO}$ (5.973\%) and $\mathrm{MgO}(0.322 \%)$. The density of VG69 organophilic clay is $1.69 \mathrm{~g} / \mathrm{cm}^{3}$. The VG69 organophilic clay is supplied by Bental Company.

The X-ray diffraction analysis of VG69 organophilic clay was performed using the Miniflex 300/600 diffractometer with $\mathrm{Cu}$-Ka radiation. The X-ray diffractogram of VG69 organophilic clay (Fig. 2) indicates that our VG69 is mainly composed of montmorillonite, with some impurities that consist of kaolinite, quartz and calcite.

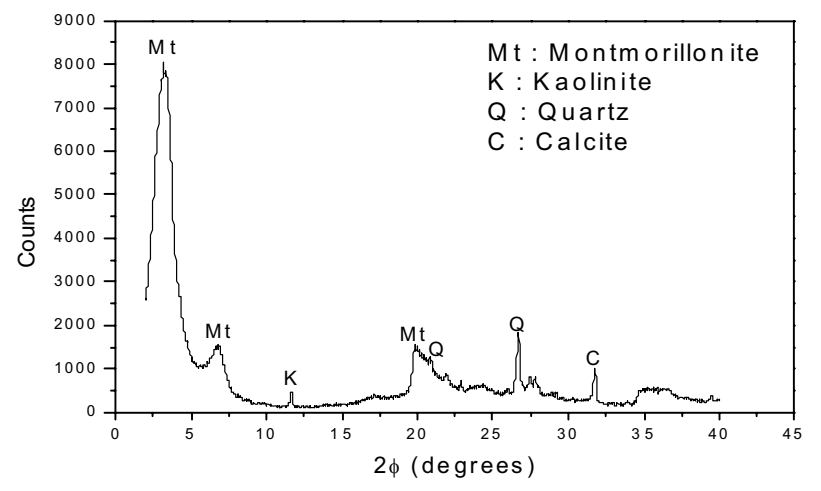

Fig. 2 X-ray diffraction of VG69 organophilic clay

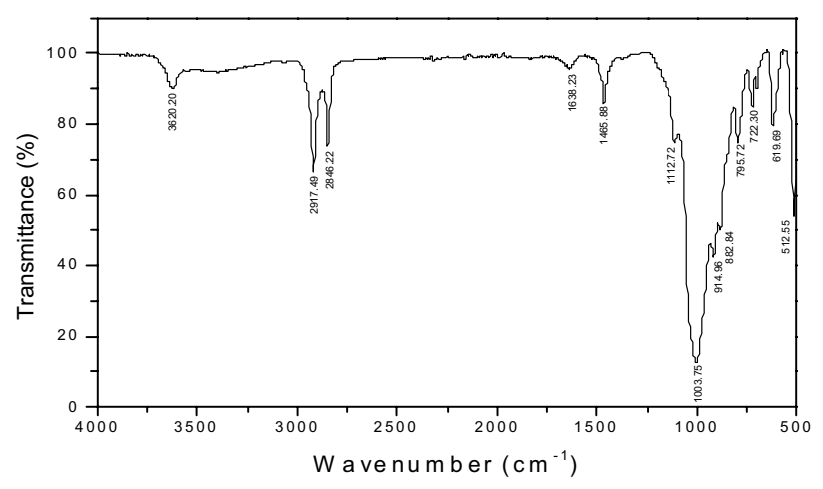

Fig. 3 FTIR spectrum of VG69 organophilic clay

The IR spectrum of the VG69 organophilic clay is shown in Fig. 3. The wavenumber at $3620.20 \mathrm{~cm}^{-1}$ corresponds to stretching vibrations of hydroxyl groups attached to the octahedral layer (Khenifi et al. 2007). The wavenumbers at 2917.49 and $2846.22 \mathrm{~cm}^{-1}$ are attributed to the asymmetric/symmetric stretching of $\mathrm{C}=\mathrm{H}$ (Kherroub et al. 2014). The wavenumbers located at 1638.23 and $1465.88 \mathrm{~cm}^{-1}$ are attributed to stretching vibrations of the $\mathrm{OH}$ group of the water content (Cherifi-Naci et al. 2016). The wavenumbers at $1112.72,1003.75$ and $914.96 \mathrm{~cm}^{-1}$ are attributed to the stretching vibrations of the Si-O link (Kherroub et al. 2014). The sharing of the $\mathrm{OH}$ group of atoms $\mathrm{Fe}$ and $\mathrm{Al}$ in the octahedral position can move the $\mathrm{Al}-\mathrm{OH}$ vibrations to lower frequencies around $882.84,795.72$ and $722.30 \mathrm{~cm}^{-1}$. The wavenumber at $619.69 \mathrm{~cm}^{-1}$ corresponds to vibrations of $\mathrm{Mg}-\mathrm{O}$ and $\mathrm{Mg}-\mathrm{OH}$. The wavenumber at $512.55 \mathrm{~cm}^{-1}$ is attributed to bending vibrations of the $\mathrm{Si}-\mathrm{O}-\mathrm{Al}$ and $\mathrm{Si}-\mathrm{O}-\mathrm{Mg}$ bonds .

\section{Samples preparation of muds}

There is not one standard formulation of muds, but many different formulations. Indeed, the latter will often be a function of the type of formations traversed during drilling, but

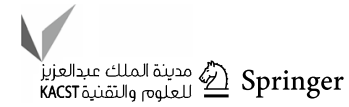


also of the depth of this one, the type of drilling, cost and environmental constraints. The formulation of these fluids is, therefore, a complicated exercise. In this study, we propose the formulation described in Table 4, these muds are prepared by successively adding the products under strong agitation $(600 \mathrm{rpm})$ carried out by a magnetic stirrer for $2 \mathrm{~h}$.

\section{Estimation of the stability of drilling muds by centrifugation}

Centrifugation is carried out using the Hettich Ultracentrifuge on different samples, in order to determine the stability of the drilling muds. The centrifugation parameters are: the speed of $600 \mathrm{rpm}$, the duration of $10 \mathrm{~min}$ and the temperature of $20^{\circ} \mathrm{C}$. We have measured the volume of water discharged. The stability of each sample was determined by Eq. 1 (Abdurahman et al. 2012).

Drilling muds stability $=\left(1-\frac{\text { Water separated }}{\text { Water content }}\right) \times 100$

\section{Rheological measurements}

The rheological measurements were performed by using a torque controlled rheometer (Discovery Hybrid Rheometer DHR2 from TA instrument), equipped with a cone-plane geometry (diameter: $60 \mathrm{~mm}$; angle: $2^{\circ}$; gap: $54 \mu \mathrm{m}$ ). It has a Peltier temperature control system that allows having a very quick response to any change in temperature range to -40 at $200{ }^{\circ} \mathrm{C}$. In order to prevent changes in composition during measurements due to water evaporation, a solvent trap was placed around the measuring device.

The hysteresis loop test consisted of three stages:

- The shear rate was linearly increased from $0.001 \mathrm{~s}^{-1}$ to the maximum shear rate of $200 \mathrm{~s}^{-1}$ in $300 \mathrm{~s}$;

- The sample was sheared at the maximum shear rate of $200 \mathrm{~s}^{-1}$ for $120 \mathrm{~s}$;

- The shear rate was linearly decreased for a maximum of $200-0.001 \mathrm{~s}^{-1}$ in $300 \mathrm{~s}$.

Table 4 Formulation of drilling muds

\begin{tabular}{lllllllll}
\hline Product & Quantity & & & & & $\begin{array}{l}\text { Time of agi- } \\
\text { tation (h) }\end{array}$ & $\begin{array}{l}\text { Speed of } \\
\text { agitation } \\
\text { (rpm) }\end{array}$ \\
\hline Gasoil (ml) & 80 & 80 & 80 & 80 & 80 & 80 & 2 & 600 \\
Water (ml) & 20 & 20 & 20 & 20 & 20 & 20 & 2 & 600 \\
Versawet (wetting agent) (ml) & 2.5 & 2.5 & 2.5 & 2.5 & 2.5 & 2.5 & 2 & 600 \\
Versacoat (emulsifier) (ml) & 2.5 & 2.5 & 2.5 & 2.5 & 2.5 & 2.5 & 2 & 600 \\
VG69 organophilic clay (g) & 0 & 1 & 2 & 3 & 4 & 5 & 2 & 600 \\
\hline
\end{tabular}

The oscillatory measurements were performed at $20^{\circ} \mathrm{C}$ in the linear viscoelastic region, and the stress was increased from 0.001 to $20 \mathrm{~Pa}$ at a fixed frequency of $1 \mathrm{~Hz}$ in stress sweep experiments.

\section{Results and discussion}

\section{Effect of VG69 organophilic clay on the stability of drilling muds}

Figure 4 shows the effect of VG69 organophilic clay concentration on the stability of drilling muds, we observe that for doses of VG69 organophilic clay lower than a critical dose, an increase in the stability of drilling muds, followed by a decrease in the stability of drilling muds from the critical dose of VG69 organophilic clay. The increase in the stability of the drilling muds is due to increasing the formation of a three-dimensional network of flocculated particles in the external phase around the droplets when the quantity of particles is sufficient (Jeon and Hong 2014; Cai et al. 2019). The decrease in the stability of the drilling muds for concentrations greater than $3 \mathrm{~g}$ is probably due to the adsorption of clay particles caused by a strong repulsion between the particles and the gasoil-water interface (Dickinson 2010; Wang et al. 2020). The decrease in the stability may also be linked

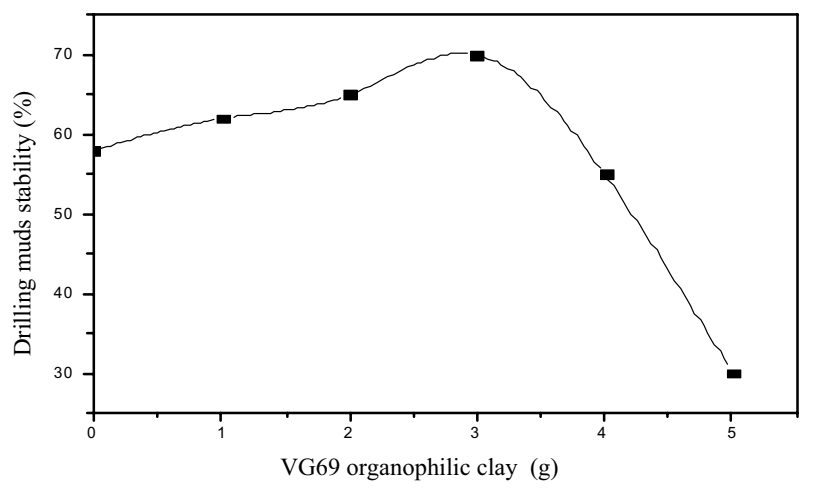

Fig. 4 Drilling muds stability as function of VG69 organophilic clay quantity 
to saturation of clay particles by the surfactant molecules (Abu-Jdayil 2011; Msadok et al. 2020).

\section{Effect of VG69 organophilic clay on the shear flow of gasoil-based drilling muds}

The flow curves of the gasoil-based drilling muds at different quantities of VG69 organophilic clay are shown in Fig. 5. It has been found that the rheological behavior of drilling muds is non-Newtonian after the yield stress. Therefore, the experimental data were best fitted to the Casson model (Bhatt et al. 2013; Ohta and Miyashita 2014):

$\tau=\tau_{0}+2 \dot{\gamma} \sqrt{\eta_{\infty} \frac{\tau_{0}}{\dot{\gamma}}}+\eta_{\infty} \dot{\gamma}$

where $\tau$ is the shear stress in $(\mathrm{Pa}) ; \tau_{0}$ is the yield stress in $(\mathrm{Pa}) ; \dot{\gamma}$ is the shear rate $\left(\mathrm{s}^{-1}\right)$ and $\eta_{\infty}$ is the viscosity at an infinite shear rate (Pa s). From Fig. 5, we notice that for the same shear rate, an increase in the shear stress as a function of the increase in the quantity of the clay added in gasoilbased drilling muds.

Table 5 shows the increase in the yield stress and viscosity at infinite shear rate as a function of VG69 organophilic clay quantity in drilling muds. The increase in the quantity of VG69 led to an increase in the yield stress, which indicates that the muds structure becomes rigid, dense and therefore difficult to break. The increase in the yield stress and the viscosity at in infinite shear rate is due to the creation of a three-dimensional network of edge-to-edge and face-toface interactions via double-layer repulsion between the clay particles (Bhatt et al. 2013; Akkal et al. 2013; Choo and Bai 2015). The increase in the quantity of VG69 organophilic clay in the drilling muds caused the organization of water droplets into string and clusters, resulting in an increase in the yield stress and viscosity at an infinite shear rate (Fakoya and Ahmed 2018).

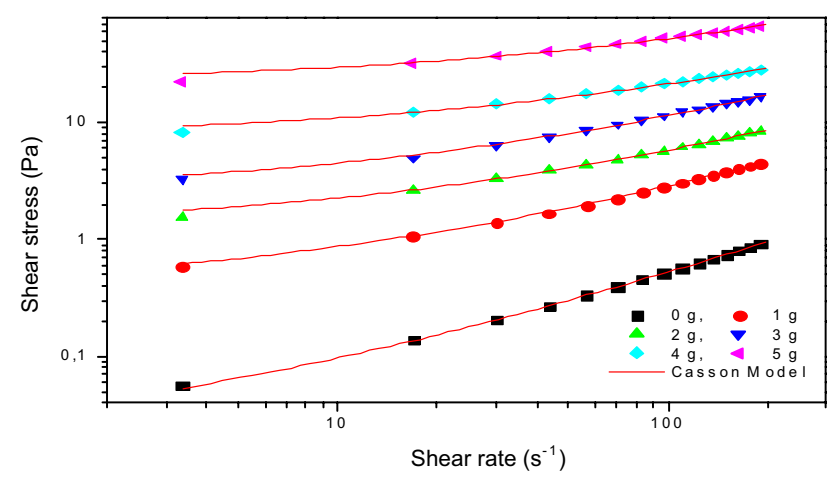

Fig. 5 Shear stress as a function of shear rate at different quantities of VG69. The solid lines correspond to the curve fitting to Eq. 2
Table 5 Evolution of yield stress and viscosity at an infinite shear rate of gasoil-based drilling muds as function of VG69 organophilic clay quantity

\begin{tabular}{llll}
\hline VG69 $(\mathrm{g})$ & $\tau_{0}(\mathrm{~Pa})$ & $\eta_{\infty}(\mathrm{Pa} \mathrm{s})$ & $R^{2}$ \\
\hline 0 & 0.0143 & 0.0036 & 0.999 \\
1 & 0.308 & 0.013 & 0.999 \\
2 & 1.185 & 0.017 & 0.999 \\
3 & 2.371 & 0.034 & 0.998 \\
4 & 7.315 & 0.037 & 0.998 \\
5 & 21.536 & 0.067 & 0.994 \\
\hline
\end{tabular}

\section{Effect of VG69 organophilic clay on the viscoelasticity of drilling muds}

Figure 6 shows the variation of storage modulus $\left(G^{\prime}\right)$ and loss modulus $\left(G^{\prime \prime}\right)$ as a function of shear stress for different concentrations of VG69 organophilic clay. From Fig. 6, it can be noted that for all quantities of VG69 added in the gasoil-based drilling muds, the storage modulus $\left(G^{\prime}\right)$ and loss modulus $\left(G^{\prime \prime}\right)$ are independent of the shear stress up to a critical shear stress value beyond which they become dependent on the shear stress. For shear greater than the critical shear stress $\left(\tau_{c}\right)$, the loss modulus $G^{\prime \prime}$ becomes greater than the storage modulus $G^{\prime}$, indicating a preponderance of the viscous nature in drilling muds. The critical shear stress (stress yield) in which the storage and loss modulus were equal $\left(G^{\prime}=G^{\prime \prime}\right)$, it has been used to characterize the effect of VG69 on the viscoelasticity of gasoil-based drilling (Bui et al. 2012; Werner et al. 2017; Moussaoui et al. 2017).

Figure 7 shows the variation of critical shear stress as a function of VG69 organophilic clay quantity added in gasoil-based drilling muds. It is clear that the increase in the quantity of VG69 organophilic clay resulted in an increase in the viscoelasticity of gasoil-based drilling muds. The increase in the critical shear stress with the dose of VG69

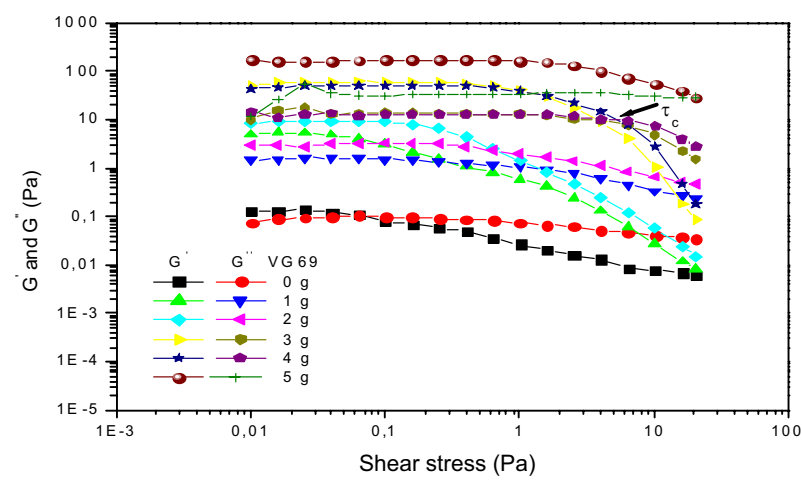

Fig. 6 Storage modulus $G^{\prime}$ and loss modulus $G^{\prime \prime}$ as a function of shear stress for different quantities of VG69 organophilic clay

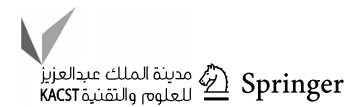




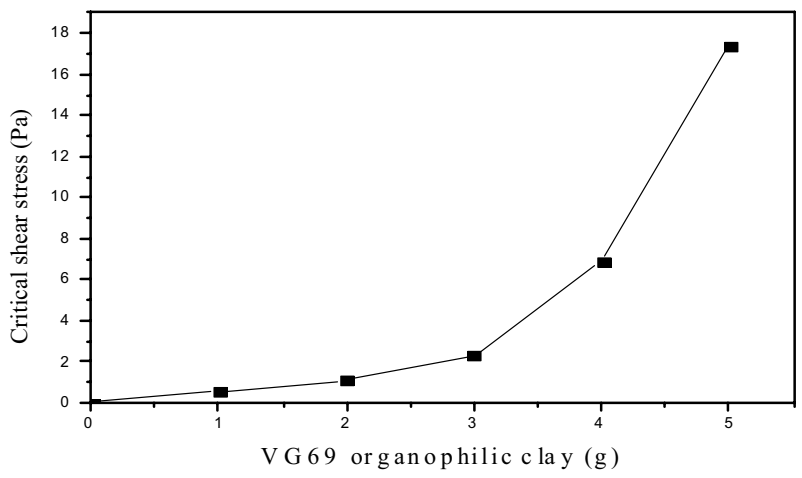

Fig. 7 Variation of critical shear stress as a function of VG69 organophilic clay quantity

organophilic clay is due to the continuous hydration reaction (Li et al. 2019).

\section{Validation of Casson model}

In order to valid the use of the Casson model for the objective of fitting the experimental data of flow curves of gasoilbased drilling muds, we made a comparison between the yield stress determined by the Casson model and the Vipulanandan model using Eq. 3 (Vipulanandan and Mohammed 2014; Mohammed 2018; Tchameni et al. 2019; Afolabi et al. 2019; Afolabi and Yusuf 2020) based on the yield stress (critical shear stress) determined by the oscillatory measurement (Yoon and Mohtar 2013; Shakeel et al. 2020).

$\tau=\tau_{0}+\frac{\dot{\gamma}}{A+B \dot{\gamma}}$

where $\tau$ is the shear stress in $(\mathrm{Pa}) ; \tau_{0}$ is the yield stress in $(\mathrm{Pa}) ; \dot{\gamma}$ is the shear rate $\left(\mathrm{s}^{-1}\right)$; $\mathrm{A}$ is the model parameter $(\mathrm{Pa} \mathrm{s})^{-1}$ and $\mathrm{B}$ is the model parameter $(\mathrm{Pa})^{-1}$.

The comparison of the yield stress values obtained using the rheological models: Casson and Vipulanandan with the oscillatory measurement is shown in Fig. 8. A good concordance was found between the yield stress obtained by Casson model and the oscillatory measurement for all quantities of VG69 organophilic clay added to drilling muds. However, the range between the yield stress obtained by Vipulanandan model and oscillatory measurement is very significant. Although the fitting of the flow curves of the gasoil-based drilling muds at different quantities of VG69 organophilic clay obtained by the Vipulanandan model gave values of the correlation coefficient $R^{2}$ greater than 0.98 , the Casson model remain the better for fitting the rheological data of gasoil-based drilling muds, due to the good concordance which was found between the yield stress obtained by this model and the oscillatory measurement.

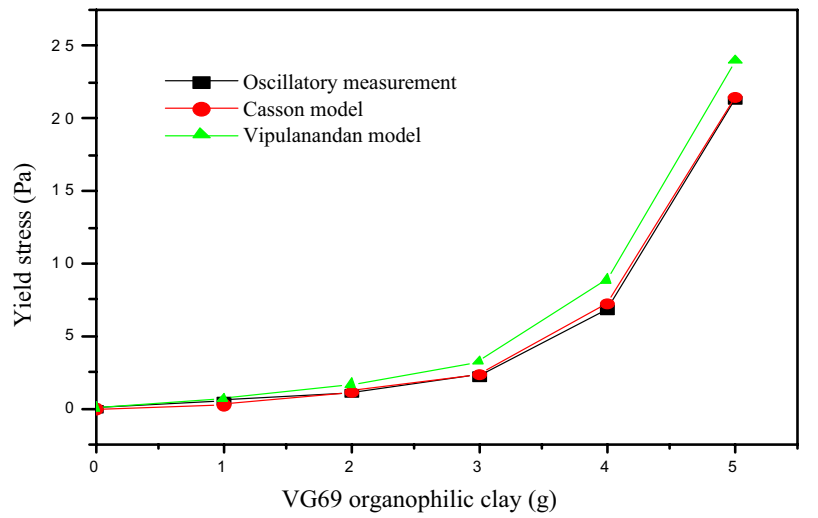

Fig. 8 Comparison of the yield stress obtained by the Casson model and the Vipulanandan model with the oscillatory measurement

\section{Effect of VG69 organophilic clay on the thixotropy of drilling muds}

The thixotropic loops of the drilling muds as a function of the VG69 organophilic clay are shown in Fig. 9. It is clear that the downward curves are under the upward curves, which indicates a positive thixotropic behavior.

In order to evaluate the effect of VG69 organophilic clay on the thixotropy of drilling muds, we calculated the area between the upward and downward curves using the data analysis option of TA Instruments Trios v4.2.1.36612. Figure 10 shows an increase in the thixotropic area of gasoil-based drilling muds as a function of the quantity of VG69 organophilic clay. These results confirm the same work published by Msadok et al. (2020) which showed that the thixotropy of gasoil-based drilling muds increases with the concentration of organoclay. This behavior could be explained by the increased cohesive forces and interactions of the clay particles reinforcing the three-dimensional structure through the formation of flocs or aggregates of particles (Hammadi et al. 2014). At high quantity of clay, the Brownian motion is important and the van der Waals

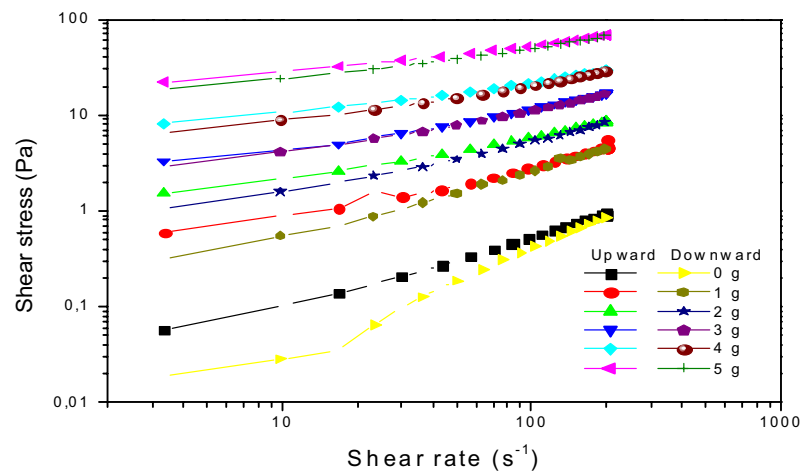

Fig. 9 Thixotropic behavior of drilling muds for different quantities of VG69 organophilic clay 


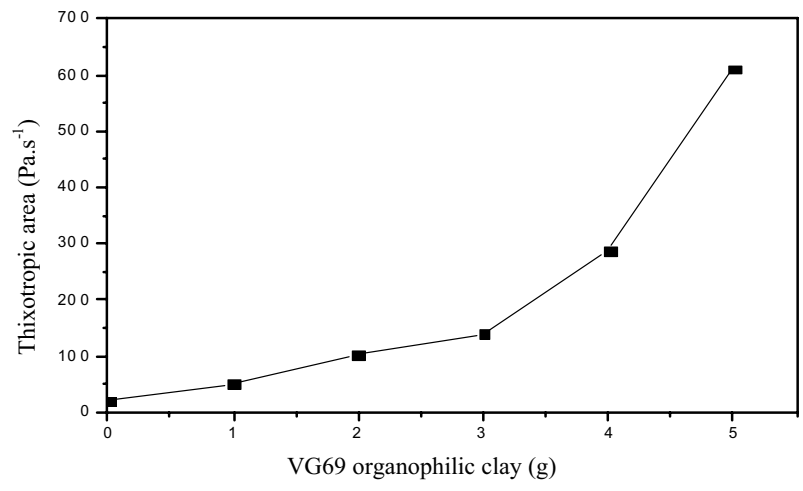

Fig. 10 Thixotropic loop area of gasoil-based drilling muds as function of VG69 organophilic clay quantity

attraction forces can cause the increase attraction of water droplets, leading an increase in the thixotropic properties of gasoil-based drilling muds (Le Pluart et al. 2004; Huang et al. 2016).

\section{Conclusion}

The effect of VG69 organophilic clay on the stability and rheological properties of gasoil-based drilling muds has been studied. It was found, on the one hand, that for quantities of VG69 organophilic clays less than $3 \mathrm{~g}$, there is an increase in the percentage of stability of gasoil-based drilling muds, and on the other hand that for quantities of VG69 organophilic clays greater than $3 \mathrm{~g}$, there is a decrease in the percentage of stability of gasoil-based drilling muds. The increase in the quantity of VG69 organophilic clay in the gasoil-based drilling muds has led to an increase in the yield stress, the viscosity at an infinite shear rate, the viscoelasticity and the thixotropic properties of drilling muds. This work could be deepened and completed in the experimentation (zetametric and filtrate tests) and by the modeling of thixotropy. The effect of other types of clays such as Geltone and Laponite as well as other additives such as zinc oxide nanoparticles and Poly-Salt polymer on the rheological behavior of the gasoil-based drilling muds in further studies could be also investigated.

Acknowledgements The authors give a lot of thanks the Laboratory for Analysis of Petroleum Products (LAPP) at the company Naftal of Sidi Bel Abbes, Algeria, for physical properties of gasoil and surfactants, the Laboratory of Chemistry Materials (LCM) at Oran 1 Ahmed Ben Bella University, Algeria, for the Infrared spectroscopic measurement and the Laboratory of Catalysis and Synthesis in Organic Chemistry (LCSOC) at Abou Bekr Belkaid Tlemcen University, Algeria, for the $\mathrm{X}$-ray diffraction analysis.
Open Access This article is licensed under a Creative Commons Attribution 4.0 International License, which permits use, sharing, adaptation, distribution and reproduction in any medium or format, as long as you give appropriate credit to the original author(s) and the source, provide a link to the Creative Commons licence, and indicate if changes were made. The images or other third party material in this article are included in the article's Creative Commons licence, unless indicated otherwise in a credit line to the material. If material is not included in the article's Creative Commons licence and your intended use is not permitted by statutory regulation or exceeds the permitted use, you will need to obtain permission directly from the copyright holder. To view a copy of this licence, visit http://creativecommons.org/licenses/by/4.0/.

\section{References}

Abdurahman NH, Rosli YM, Azhari NH, Hayder BA (2012) Pipeline transportation of viscous crudes as concentrated oil-in-water emulsions. J Pet Sci Eng 90:139-144

Abu-Jdayil B (2011) Rheology of sodium and calcium bentonite-water dispersions: effect of electrolytes and aging time. Int J Miner Process 98(3-4):208-213

Afolabi RO, Yusuf EO (2020) Modification of the Vipulanandan rheological model with correlation for temperature and electrolyte effect on drilling muds. Adv Powder Technol 31(1):312-322

Afolabi RO, Yusuf EO, Okonji CV, Nwobodo SC (2019) Predictive analytics for the vipulanandan rheological model and its correlative effect for nanoparticle modification of drilling mud. J Pet Sci Eng 183:106377

Aftab A, Ismail AR, Ibupoto ZH, Akeiber H, Malghani MGK (2017) Nanoparticles based drilling muds a solution to drill elevated temperature wells: a review. Renew Sustain Energy Rev 76:1301-1313

Aftab A, Ali M, Sahito MF, Mohanty US, Jha NK, Akhondzadeh H, Iglauer S (2020) Environmental friendliness and high performance of multifunctional tween $80 / \mathrm{ZnO}$-nanoparticles-added water-based drilling fluid: an experimental approach. ACS Sustain Chem Eng 8(30):11224-11243

Agin F, Sharifnik MA, Dijvejin ZA, Nasiri A, Valizadeh M, Rostamabadi HS (2019) The effect of 1, 6-hexamethylenediamine on thermal stability and shale cutting recovery of heavy weight drilling fluids. J Pet Explor Prod Technol 9(3):2053-2064

Akkal R, Cohaut N, Khodja M, Ahmed-Zaid T, Bergaya F (2013) Rheo-SAXS investigation of organoclay water in oil emulsions. Colloids Surf A 436:751-762

Ali M, Jarni HH, Aftab A, Ismail AR, Saady NMC, Sahito MF, Keshavarz A, Iglauer S, Sarmadivaleh M (2020) Nanomaterial-based drilling fluids for exploitation of unconventional reservoirs: a review. Energies 13(13):3417

Bharath G, Hai A, Rambabu K, Banat F, Jayaraman R, Taher H, Schmidt JE (2020) Systematic production and characterization of pyrolysis-oil from date tree wastes for bio-fuel applications. Biomass Bioenergy 135:105523

Bhatt J, Somani RS, Mody HM, Bajaj HC (2013) Rheological study of organoclays prepared from Indian bentonite: effect of dispersing methods. Appl Clay Sci 83:106-114

Bui B, Saasen A, Maxey J, Ozbayoglu ME, Miska SZ, Yu M, Takach NE (2012) Viscoelastic properties of oil-based drilling fluids. Annu Trans Nordic Rheol Soc 20:33-47

Cai X, Li C, Tang Q, Zhen B, Xie X, Zhu W, Wang L (2019) Assembling kaolinite nanotube at water/oil interface for enhancing Pickering emulsion stability. Appl Clay Sci 172:115-122

Cherifi-Naci H, Bougherara S, Louhab K (2016) Synthesis and characterization of Sb-PILCs bentonite clay mineral used as adsorbent. Alger J Environ Sci Technol 2(1):46-51

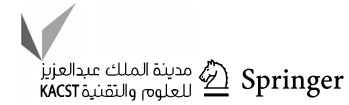


Choo KY, Bai K (2015) Effects of bentonite concentration and solution $\mathrm{pH}$ on the rheological properties and long-term stabilities of bentonite suspensions. Appl Clay Sci 108:182-190

Coussot P, Bertrand F, Herzhaft B (2004) Rheological behavior of drilling muds, characterization using MRI visualization. Oil Gas Sci Technol 59(1):23-29

Dickinson E (2010) Food emulsions and foams: Stabilization by particles. Curr Opin Colloid Interface Sci 15(1-2):40-49

Fakoya MF, Ahmed RM (2018) A generalized model for apparent viscosity of oil-based muds. J Pet Sci Eng 165:777-785

Gbadamosi AO, Junin R, Abdalla Y, Agi A, Oseh JO (2019) Experimental investigation of the effects of silica nanoparticle on hole cleaning efficiency of water-based drilling mud. J Pet Sci Eng 172:1226-1234

Geng T, Qiu Z, Zhao C, Zhang L, Zhao X (2019) Rheological study on the invert emulsion fluids with organoclay at high aged temperatures. Colloids Surf A 573:211-221

Hammadi L, Boudjenane N, Belhadri M (2014) Effect of polyethylene oxide (PEO) and shear rate on rheological properties of bentonite clay. Appl Clay Sci 99:306-311

Hermoso J, Martinez-Boza F, Gallegos C (2015) Influence of aqueous phase volume fraction, organoclay concentration and pressure on invert-emulsion oil muds rheology. J Ind Eng Chem 22:341-349

Huang X, Jiang G, He Y, An Y, Zhang S (2016) Improvement of rheological properties of invert drilling fluids by enhancing interactions of water droplets using hydrogen bonding linker. Colloids Surf A 506:467-475

Ibrahim DS, Sami NA, Balasubramanian N (2017) Effect of barite and gas oil drilling fluid additives on the reservoir rock characteristics. J Pet Explor Prod Technol 7(1):281-292

Ismail AR, Aftab A, Ibupoto ZH, Zolkifile N (2016) The novel approach for the enhancement of rheological properties of waterbased drilling fluids by using multi-walled carbon nanotube, nanosilica and glass beads. J Pet Sci Eng 139:264-275

Jeon TY, Hong JS (2014) Stabilization of O/W emulsion with hydrophilic/hydrophobic clay particles. Colloid Polym Sci 292(11):2939-2947

Jiang G, He Y, Huang X, Deng Z, Qin Y (2016) A high-density organoclay-free oil base drilling fluid based on supramolecular chemistry. Pet Explor Dev 43(1):131-135

Khenifi A, Bouberka Z, Sekrane F, Kameche M, Derriche Z (2007) Adsorption study of an industrial dye by an organic clay. Adsorption 13(2): 149-158

Kherroub DE, Belbachir M, Lamouri S (2014) Preparation and characterization of organophilic montmorillonite (12-maghnite) using Algerian clay. Orient J Chem 30(4):1647-1651

Le Pluart L, Duchet J, Sautereau H, Halley P, Gerard JF (2004) Rheological properties of organoclay suspensions in epoxy network precursors. Appl Clay Sci 25(3-4):207-219

Li W, Zhao X, Ji Y, Peng H, Li Y, Liu L, Han X (2016) An investigation on environmentally friendly biodiesel-based invert emulsion drilling fluid. J Pet Explor Prod Technol 6(3):505-517

Li W, Shaikh FU, Wang L, Lu Y, Wang B, Jiang C, Su Y (2019) Experimental study on shear property and rheological characteristic of superfine cement grouts with nano- $\mathrm{SiO}_{2}$ addition. Constr Build Mater 228:117046

Medhi S, Chowdhury S, Gupta DK, Mazumdar A (2020) An investigation on the effects of silica and copper oxide nanoparticles on rheological and fluid loss property of drilling fluids. J Pet Explor Prod Technol 10(1):91-101

Mohamed AI, Hussein IA, Sultan AS, Al-Muntasheri GA (2018) Use of organoclay as a stabilizer for water-in-oil emulsions under hightemperature high-salinity conditions. J Pet Sci Eng 160:302-312

Mohammed AS (2018) Vipulanandan model for the rheological properties with ultimate shear stress of oil well cement modified with nanoclay. Egypt J Pet 27(3):335-347

Moussaoui N, Hammadi L, Boudjenane NE, Denine RR (2017) Development of multiple $\mathrm{W} / \mathrm{O} / \mathrm{W}$ emulsions used in pharmaceutical field: effect of additives and insulin on physicochemical and rheological stability of emulsions. Colloid Polym Sci 295(1):125-133

Msadok I, Hamdi N, Rodríguez MA, Ferrari B, Srasra E (2020) Synthesis and characterization of Tunisian organoclay: application as viscosifier in oil drilling fluid. Chem Eng Res Des 153:427-434

Ohta T, Miyashita M (2014) DNS and LES with an extended Smagorinsky model for wall turbulence in non-Newtonian viscous fluids. J Nonnewton Fluid Mech 206:29-39

Ruschel CFC, Huang CT, Samios D, Ferrão MF, Yamamoto CI, Plocharski RCB (2015) Environmentally friendly determination of quality parameters of biodiesel/diesel blends using Fourier transform infrared spectra. J Am Oil Chem Soc 92(3):309-315

Salehnezhad L, Heydari A, Fattahi M (2019) Experimental investigation and rheological behaviors of water-based drilling mud contained starch-ZnO nanofluids through response surface methodology. J Mol Liq 276:417-430

Shakeel A, Kirichek A, Chassagne C (2020) Effect of pre-shearing on the steady and dynamic rheological properties of mud sediments. Mar Pet Geol 116:104338

Stuckman MY, Lopano CL, Berry SM, Hakala JA (2019) Geochemical solid characterization of drill cuttings, core and drilling mud from Marcellus Shale Energy development. J Nat Gas Sci Eng 68:102922

Tchameni AP, Zhao L, Ribeiro JX, Li T (2019) Evaluating the thermal effect on the rheological properties of waste vegetable oil biodiesel modified bentonite drilling muds using Vipulanandan model. High Temp High Press 48(3):207-232

Vipulanandan C, Mohammed AS (2014) Hyperbolic rheological model with shear stress limit for acrylamide polymer modified bentonite drilling muds. J Pet Sci Eng 122:38-47

Wang Y, Yan W, Jia X, Cheng Y (2020) Improving stability of gliadin-based Pickering emulsions by deamidation. J Food Eng 271:109773

Werner B, Myrseth V, Saasen A (2017) Viscoelastic properties of drilling fluids and their influence on cuttings transport. J Pet Sci Eng $156: 845-851$

Yoon J, Mohtar CE (2013) Dynamic rheological properties of sodium pyrophosphate-modified bentonite suspensions for liquefaction mitigation. Clays Clay Miner 61(4):319-327

Zhou D, Zhang Z, Tang J, Wang F, Liao L (2016) Applied properties of oil-based drilling fluids with montmorillonites modified by cationic and anionic surfactants. Appl Clay Sci 121:1-8

Publisher's Note Springer Nature remains neutral with regard to jurisdictional claims in published maps and institutional affiliations. 